\title{
Research on the development strategy of Pingdingshan iron and steel industry cluster with Wugang Company as the core
}

\author{
Shuai Wang ${ }^{*}$ and Hongxiang Cao \\ School of Management Engineer, Zhengzhou University \\ *Corresponding author: 1024333549@qq.com
}

\begin{abstract}
Arouse the great potential of the industrial clusters will play a significant role in promoting the development of local WuGang company. The article takes the Pingdingshan City as the research object, who is a typical resource-based city and develops on the basis of the local resources of coal and iron ore, the core enterprise WuGang Company is a large state-owned enterprise based on the wide and thick steel plate production. Many problems also exit in the cluster innovation, company network construction, company cooperation. The article is from the perspective of steel industry cluster and cluster innovation. Firstly, the article introduces the correlation theory about the steel industry cluster and the basic development information of Pingdingshan steel industry cluster, and promotes the research purpose and meaning. The article will give the analysis to the problems from the Pingdingshan steel industry cluster and develop the reform proposals and development strategy according to the actual situation.
\end{abstract}

\section{Background}

\subsection{Introduction to the concept of iron and steel industry cluster}

Cluster is a small and medium-sized enterprise and institutions of a specific industry in a large number of clusters gathered in a certain geographical range and the formation of a stable, sustainable competitive advantage. There are many types of industrial clusters, the iron and steel industry cluster is a form of resource-based industrial cluster the classification, is relying on the iron ore resources, through the development and utilization of resources, production and processing as a link, regional resource-based industrial clusters and the large and medium-sized state-owned steel enterprises as the core form. The iron and steel industry cluster mainly relies on the iron ore this non renewable resources, the industrial structure and the supply chain has led to a lack of diversity and complementarity, limits among organizations of the steel industry chain of cooperation, the cluster characteristics of its network is difficult to fully show.

\subsection{Introduction to the basic situation of Pingdingshan iron and steel industry cluster}

Pingdingshan city is located in central Henan Province, has a strong industrial foundation and rich mineral resources, iron ore resources in Wugang city under the jurisdiction of the rich, as one of China's ten largest iron ore district, Wugang iron and steel company core enterprise clusters in Pingdingshan in Wugang province. Currently, cluster enterprise network there are 8 mining enterprises, 2 iron enterprises, 2 steel companies, 2 enterprises, 23 steel plate 
processing enterprises, 12 steel, more than and 140 steel materials production enterprises and sales enterprises, the formation of a from mining, beneficiation, ironmaking, steelmaking, rolling steel, steel processing to complete the production materials of iron and steel industry chain. Pingdingshan iron and steel industry cluster compared to other local industrial clusters, strong basic, the total amount of more development speed, well-known brands are more prominent.

\section{Development status of Pingdingshan iron and steel industry cluster}

\section{1 development course and current situation of Pingdingshan iron and steel industry cluster}

\subsubsection{The development course of core enterprise Wugang company}

The formation of iron and steel industry in Pingdingshan is to start from the core business of Wugang company, Wugang company was founded in 1970, formerly the national subordinate enterprises, as the beginning of national defense project construction. In June 1986, the first phase of Wugang steelmaking project was completed and put into operation, which ended the history of China's iron and steel industry. In 2000, the Wugang municipal government support, set up with Steel Corp and other enterprises, thus gradually established a relatively complete industrial chain of iron and steel, Pingdingshan iron and steel industry of the early embryo. Since then, the rapid rise of Wugang Company. At present, the total assets of over ten billion yuan, with more than 2 employees, operate income of over 20 billion yuan of the actual production and operation capacity.

\subsubsection{General situation of Pingdingshan iron and steel industry cluster and its development status}

There are about more than and 210 enterprises in the cluster enterprise network. Cluster of coal enterprises and steel enterprises. At present, there are four main enterprises in the cluster, which runs through the production chain of the whole industrial cluster.

Henan iron and Steel Group Wuyang Mining Co., Ltd., is a large state-owned iron ore production enterprises in Henan province. Their reserve of 3.23 tons of ore reserves, Wugang is an indispensable and important raw material base for the company. An iron and Steel Group, Wuyang iron and Steel Co., Ltd. has its own iron ore and the surrounding large and small iron ore for the production of blast furnace to provide adequate supply of raw materials. What the Pingdingshan Coal Group as the iron and steel industry of coal resources supply enterprises is the largest enterprise in the cluster, but also the domestic ultra million tons of large coal production bases, coal production capacity of 70 million tons, production and sales in the forefront of the country. Pingdingshan Yao Meng Power Engineering Co., Ltd. is one of the backbone power plants in Central China power grid, in order to provide power energy.

At present, Wuyang special steel rolling mineral company mining and processing, in the same sintering and pelletizing and Steel Corp and Wuyang pig iron smelting Steel Corp formed a complete industrial chain, between the upper and lower process complementary advantages, reduce the circulation, reduce logistics costs, achieve mutual benefit and win-win three party. Downstream machinery manufacturing industry formed a steel plate, composite plate, mechanical processing, equipment manufacturing, the industry chain.

\subsection{Organizational structure of Pingdingshan iron and steel industry cluster}

Single core cluster is also called the wheel type cluster on a single core network only one core enterprise and other enterprises around the core enterprise around, provide spare parts production and a production process or other production and service life of the. Pingdingshan iron and steel industry with the main characteristics of the single core cluster, is the development of small and medium-sized enterprises in Wugang's large state-owned enterprises such as the core to drive around the whole cluster in Wugang company's value chain and the production process as the main line 
of division of labor, the cluster followed by the raw material supplier (Wuyang mineral company, and Steel Corp) - pig iron producers (with Steel Corp) - steel enterprises (Wugang) - steel scrap processing enterprises (with Steel Corp) Sales trader (Wugang tengwu Co.) in series. Wugang brand has a strong influence in the international wide steel plate market. Wugang Company is one of the five production plants with the influence of the world by virtue of its technological advantages, and it has a significant market. With these advantages, Wugang, the company holds most of the resources of the enterprise network, but also determines the direction of development of other enterprises. Wugang company with raw material suppliers and waste processing enterprises, etc. have maintained a high degree of vertical cooperation, but also the existence of long-term trading and commitment.

\section{The main problems existing in the development of Pingdingshan iron and steel industry cluster}

\section{1 affected by the macro factors, the company suffered serious losses}

By the impact of the global economic slowdown and the negative impact of China's economic growth, automobile, shipbuilding, machinery manufacturing and other downstream steel industry slowdown, weakens domestic demand for steel. China's steel industry average sales profit margin has dropped to $0.47 \%$, large and medium-sized enterprises expanded to $32.5 \%$, while China's steel industry's huge production capacity, further exacerbated the disorderly competition in the steel industry. Wugang Company is a professional manufacturer of wide heavy plate, although the production technical level is at the leading position in the same industry, but due to the homogenization of competition to high-end products spread, makes the profit level of iron and steel enterprises continue to decline. The competition strategy of Wugang variety and market for the other medium and heavy plate enterprises are facing the unprecedented challenge and impact.

\subsection{Innovation capacity of the cluster is generally insufficient}

At present, although the formation of the opponent to imitate the unique competitive advantage of Pingdingshan iron and steel industry core competitiveness in the wide and heavy plate production, but the lack of innovation ability and professional talents are weak still exist in other areas of production of Wugang steel company, cluster enterprises in the overall innovation capability is weak.

First of all, from the development of iron and steel industry clusters in Pingdingshan, to the traditional industry and mining of mineral resources industry, the product is still in the stage of the supply of raw materials or semi-finished products, it is difficult to form a long-term competitive advantage, reproducible. Secondly, the Pingdingshan iron and steel industry cluster has not formed the perfect innovation mechanism and the innovation network, the cluster sustainable development ability is worrying. In terms of the cluster enterprise, the removal of large state-owned enterprises such as Wugang, other companies generally lack of R \& D institutions and R \& D team building, talent education and training system is still not perfect. Most of the enterprises in the cluster are low in the proportion of product innovation. Again, the lack of enhancement of cluster innovation capability of Pingdingshan iron and steel industry are limited to the professional talents, different from the other in the more developed areas of iron and steel industry clusters, has a strong research team supported by universities in the province ranked relatively in the metallurgical field. This is based on the small town developed in the industrial cluster of enterprises in the individual, family oriented enterprises, low starting point, small scale, in attracting professional talent, there are obvious shortcomings.

\subsection{The lack of intermediary organizations}


Pingdingshan iron and steel industry cluster enterprise network within the form of intermediary service agencies specialized in cluster within the enterprise services. At present, the development of cluster only focus on the development of the core enterprise itself, the lack of targeted financial intermediaries, recruitment agencies, productivity service center, the assessment of advisory bodies and related legal advisory bodies, etc.. Wugang City, there are only two consulting companies and enterprises in the cluster and the demand is not matching; number within the cluster of legal advisory bodies, but for business in Wugang city is not strong; only through the recruitment network announced the recruitment information, recruitment information for no complex. In addition, due to the lack of financial intermediaries in the cluster, many small and medium-sized enterprises in the bank to obtain funds through bank loans to support the case, mainly adopts private funds to raise funds to expand production and operation.

\subsection{Mining waste discharge is serious in the cluster}

Pingdingshan city is a typical resource-based city, mainly depends on iron ore resources and coal resources, but because of the non renewable resources, the development of the cluster also has an important impact. At present, the northern city of Pingdingshan, in the West due to excessive exploitation of coal resources has been formed in subsidence area contiguous, mining difficult again. As the development and utilization of coal technology behind, the recovery rate of mining and mining waste two development and utilization of technology is still scarce, resulting in a large number of waste of resources available. With the exploitation of resources, the collapse accidents and natural disasters have destroyed the production and life in the cluster.

\section{The development strategy of Pingdingshan iron and steel industry cluster}

In this paper, through the support of relevant industrial cluster innovation theory, and analysis of the status quo and problems faced by Pingdingshan iron and steel industry cluster, the development strategy of Pingdingshan iron and steel industry cluster is proposed the following suggestions.

\subsection{To guide the implementation of professional management strategy of Wugang company}

Wugang company should rely on its own technical advantages and advantages in the production of extra thick steel plate, to take specialized business strategy.

First of all, the market development should be fully grasped. For Wugang companies, the first job is the market and the contract. To contract information, market development, export increment, volume and price balance and incentive assessment is the most important. Secondly, it should establish the concept of the customer as the center. Make clear the demand of terminal users, through appropriate to extend the service chain and product chain, to provide better products; to clear business direction always start production "around the customers, enterprises to form effective linkage and quick reaction ability of problem solving. Again, the Wugang company should adhere to the "new special" road. To adhere to carry forward the Wugang Company in the brand, high-end product line, product research and development capabilities and the advantages of high-end market. Only sustained development of new products, committed to the development of high-end market to meet the needs of the domestic and international market for heavy steel plate.

\subsection{To establish the cluster innovation based on Knowledge Network}

\subsubsection{Encourage innovation and interaction among enterprises in cluster}

First, the Wugang Company as a local large-scale state-owned enterprise should act as a leading role to promote inter enterprise cooperation model. Other steel production enterprises within the cluster enterprise network, such as iron and Steel Group, etc., should be more interactive with Wugang companies to carry out product innovation, improve their production technology and scientific research level. At the same time when the other small and medium enterprises 
actively brokered area of technical innovation alliance, to carry out extensive cooperation in the field of innovation. Secondly, until the cluster enterprise network development and maturity within the cluster can be set up a research fund, funded by the various enterprises, specializing in the production and service innovation. This kind of cooperation is actually a kind of simplified technology alliance, which is helpful to the formation of the unique competitiveness of knowledge sharing, human resources and technological advantages.

\subsubsection{Seek cooperation opportunities from external agencies}

In the era of knowledge economy, enterprises should actively look for external joint venture and technical partners to improve the efficiency of cluster technology, and inject fresh vitality into cluster innovation. Enterprises within the cluster to ensure long-term stable contact with external agencies, the formation of a timely knowledge of the flow. At present, enterprises in the cluster are mostly solved by external experts to solve technical problems, and lack of long-term and stability. Wugang companies and other enterprises should establish long-term cooperation with universities in the relevant areas of expertise, such cooperation, including cooperation in the field of scientific research and talent output.

\subsection{To encourage the sharing of resources among enterprises within the cluster}

\subsubsection{Use industry website to promote the sharing of information resources between enterprises}

It should draw on the successful experience of Zhejiang's industrial clusters using network technology to promote the development of industry, to encourage the steel industry cluster to establish their own professional website. Conditions within the cluster enterprises should be established in Wugang as a benchmark for the industry's Web site, the industry will share the information in this industry. In addition to publishing the cooperation information and market dynamic information of each industry, it should also provide various policies and regulations, as well as scientific research content.

\subsubsection{Organization of industry associations to expand the sharing of knowledge resources between enterprises}

In Zhejiang, Shenzhen these industrial clusters to develop more mature areas of the association is worth our reference. Association of interests because of strong consistency and high degree of specialization often has a good ability to act, to achieve a good effect of information communication between enterprises in the same industry, develop the market in learning and training, the development of industry practices such as more likely to agree. Pingdingshan iron and steel industry cluster should draw on this form of organization, with Wugang Company as the core to establish the industry association of enterprise network, and support its development activities.

\subsection{Perfect the external environment of cluster development}

\subsubsection{To ensure the competitive order of enterprises in the cluster}

Wugang municipal government and other public management departments should take on the important task of ensuring the competitive order of the iron and steel industry cluster, strengthen its supervisory role. First, the government departments should strengthen market supervision, fight against shoddy work, shoddy, deceive customers, fake and shoddy products, the protection of intellectual property rights and patent technology. Second, in terms of specific work, technical supervision departments and industry associations should cooperate with each other, to develop industry technical standards, through industry standards to guide enterprises to upgrade technology. Third, the local government for the iron and steel industry cluster in mining enterprises, coal mining enterprises, steel enterprises, lower 
emissions disorderly exploitation costs arising from environmental pollution problems timely monitoring, and resolutely investigate and deal with illegal enterprises for fines, eliminate arbitrary row misplacing problem is.

\subsubsection{Strengthen the functions of intermediary service agencies in the inter enterprise communication}

Pingdingshan municipal government and the Wugang municipal government should support the establishment of intermediary institutions, at different levels to provide support services for the enterprise technology innovation. The enterprises in the cluster should form a close interest relationship with the intermediary organizations, and reduce the barriers of knowledge flow. Intermediary service agencies should be responsible for helping enterprises to provide cooperative information, the right choice of partners; the company released new technologies, new products, and new investment opportunities in the role of information.

\subsubsection{Create a good business environment within the cluster.}

The relationship between enterprises cannot be separated from the informal non-governmental exchanges, these activities can be a good way to cultivate corporate social responsibility, promote the exchange and sharing of knowledge. Actively carry out a variety of cultural exchange activities, to effectively promote the cluster within the enterprise to establish a harmonious and trusted business environment. The Wugang company should have such basic superior natural environment in the city, focusing on the construction of service facilities, has formed its own cultural environment, attract more investors and social capital. Various cultural undertakings should be developed in the region, to create a more harmonious social living space.

\section{References}

1. Propris, Systemic Flexibility L.D., Fragmentation and Cluster Governance . European Planning Studies Production, 2001, Vol 9

2. Meng Yue, Chi Wencheng, industrial cluster technology learning mechanism research, economic management publishing house, 2009

3. Liu Yan, empirical study on the change of China's strategic emerging industry agglomeration degree, Shanghai economic research, 2013.02

4. Liu Junying, the development of industrial agglomeration in the transformation of resource based cities -- Taking Pingdingshan city as an example, the people's forum, 2014.19

5. Wang Shuying, the evolution of industrial clusters and regional economic development research, Guangming Daily Press, 2009

6. Peng Peng, Xiao Rui, study on the transformation of resource based cities -- Taking Pingdingshan as an example, Journal of Xianning University, April 2010

7. Meng Tao, industrial cluster organization under the network perspective, China Social Science Press, 2009

8. Zhao Zhonghua, Research on the network structure and performance of innovative industrial clusters, Harbin Institute of Technology press, 2009

9. Xiong Xiaohui, "the iron and steel industry is on the verge of comprehensive loss", China Business News, 2011 